\title{
Rescue of osteoclast function by transgenic expression of kinase-deficient Src in src-1-mutant mice
}

\author{
Pamela L. Schwartzberg ${ }^{1,6}$ Lianping Xing, ${ }^{2}$ Oskar Hoffmann, ${ }^{3}$ Clifford A. Lowell, ${ }^{4}$ Lisa Garrett, ${ }^{5}$ \\ Brendan F. Boyce, ${ }^{2}$ and Harold E. Varmus ${ }^{1}$ \\ ${ }^{1} \mathrm{~N}$ ational Cancer Institute, ${ }^{2}$ Department of Pathology, University of Texas Health Science Center, San Antonio, Texas \\ 78284 USA; ${ }^{3}$ Department of Pharmacology and Toxicology, University of Vienna, Vienna, Austria; ${ }^{4}$ Department of \\ Laboratory M edicine, University of California, San Francisco, California 94143 USA; ${ }^{5} \mathrm{~N}$ ational Human Genome Research \\ Institute, N ational Institutes of Health, Bethesda, M aryland 20892 USA
}

\begin{abstract}
The Src tyrosine kinase has been implicated in a wide variety of signal transduction pathways, yet despite the nearly ubiquitous expression of c-src, src- $-1-$ mice show only one major phenotype-osteopetrosis caused by an intrinsic defect in osteoclasts, the cells responsible for resorbing bone. To explore further the role of Src both in osteoclasts and other cell types, we have generated transgenic mice that express the wild-type and mutated versions of the chicken c-src proto-oncogene from the promoter of tartrate resistant acid phosphatase (T RAP), a gene that is expressed highly in osteoclasts. We demonstrate here that expression of a wild-type transgene in only a limited number of tissues can fully rescue the src -1 - phenotype Surprisingly, expression of kinase-defective alleles of c-src also reduces osteopetrosis in src- $/$-animals and partially rescues a defect in cytoskeletal organization observed in src -1 -osteoclasts. These results suggest that there are essential kinase-independent functions for Src in vivo. Biochemical examination of osteoclasts from these mice suggest that Src may function in part by recruiting or activating other tyrosine kinases.
\end{abstract}

[Key words: Src; tyrosine kinase; transgenic mice]

Received July 8, 1997; revised version accepted August 26, 1997.

The Src tyrosine kinase is a member of a family of nine closely related tyrosine kinases defined by a common structure, including $\mathrm{SH} 2$ and $\mathrm{SH} 3$ protein interaction domains, a catalytic region, and a negative-regul atory tyrosine located near the carboxyl terminus (Brown and Cooper 1996). Much of what is known about the function of these domains has come from studies of cellular transformation either by v-src, or by activated versions of the c-src proto-oncogene. However, the function of these domains in signal transduction pathways involving endogenous Src is not well defined. Src kinase is activated by a variety of signaling pathways including stimulation of growth factor receptors, G protein-coupled receptors, oxidative and UV stress, and integrin-mediated signal transduction (Brown and Cooper 1996). Furthermore, Src has been demonstrated to regulate the activity of both potassium and N MDA channels (Holmes et al. 1996; Y u et al. 1997). To date, however, critical downstream targets of the kinase have remained controversial in many of these pathways.

Targeted gene-disruption of c-src in mi ce leads to only one major phenotype-severe osteopetrosis-with re-

${ }^{6}$ Corresponding author.

E-MAIL pams@nhgri.nih.gov; FAX (301) 496-0332. sulting thickened bone, decreased marrow space, and a failure of tooth eruption (Soriano et al. 1991). The severe morbi dity and increased mortality resulting from osteopetrosis greatly complicate analysis of Src function in other tissues and organ systems in these mice. The src $-1-$ phenotype results from an intrinsic defect in osteoclasts, the cells that resorb bone (Lowe et al. 1993). Osteoclasts are highly polarized cells of the monocytemacrophage lineage that break down bone through the actions of the ruffled border, a specialized region of the cell consisting of highly invaginated membranes surrounded by the sealing zone, where the osteoclast firmly attaches to the bone matrix (Baron et al. 1993). The ruffled border is the site of secretion of hydrogen ions and proteolytic enzymes that promote digestion of the bone matrix. Although osteoclasts are present in src- mice in normal or increased numbers, they fail to form ruffled borders and consequently do not resorb bone (Boyce et al. 1992). The osteoclast therefore strictly requires Src activity for its proper morphology and function and provides an unique cell type in which to evaluate Src function in a physiological setting.

We have developed a genetic system for studying Src function in the osteoclasts of transgenic mice by driving expression of wild-type and mutant versions of Src with 
the promoter of tartrate resitant acid phosphatase (TRAP), a gene expressed highly in osteoclasts. U sing this system, we demonstrate that Src kinase activity is not essential for rescue of the src $-1-$ phenotype. These results suggest that there are essential kinase-independent functions for Src in vivo. Furthermore, by generating src $-1-$ mice that express src in limited cell lineages, this approach may allow the analysis of Src function in other tissues in mice free from the morbidity of osteopetrosis.

\section{Results}

Generation of transgenic mice expressing c-src in osteoclasts

To achieve expression of Src in osteoclasts, we used the promoter of the gene-encoding TRAP, an enzyme highly expressed in osteoclasts. The wild-type chicken c-src cDNA was fused to the ATG and $\sim 1.8-\mathrm{kb}$ of upstream sequences of the TRAP gene, including the first exon and intron (Reddy et al. 1995), and introduced into mice by pronuclear injection (Fig. 1A). We elected to use the chicken c-src CDN A in these experiments for several reasons. First, the availability of an avian-specific monoclonal antibody allows the specific identification of the protein encoded by the transgene in mouse tissues. Second, the chicken c-src gene has been studied widely and large numbers of mutants have been characterized in this background. Furthermore, our laboratory has demonstrated previously that the chicken c-src gene can rescue a cell-spreading phenotype observed in fibroblasts derived from src-l-mice, suggesting that the chicken c-src gene is able to substitute for mouse c-src function, at least in this celltype (Kaplan et al. 1995).

Expression of the TRAPsrc ${ }^{\mathrm{WT}}$ transgene was examined in bone marrow removed from transgenic mice and cultured in the presence of 1,25 dihydroxy vitamin D3 (1,25 D3) under conditions that induce the differentiation of osteoclasts (T akahashi et al . 1988a). Four of six independent transgenic lines demonstrated 1,25 D3-dependent expression of the transgene as asssayed by reverse transcriptase (RT)-PCR (Fig. 1B.) Immunohistochemistry of bone sections from TRAPsrc mice also demonstrates that expression of the transgene in bone is restricted to osteoclasts (L. Xing and B. Boyce, unpubl.). TRAPsrc ${ }^{\mathrm{WT}}$ mRN A was also observed by N orthern analysis in a limited number of other tissues, including small intestine (in all lines examined to date), liver and kidney (3/4 lines), and thymus ( $1 / 4$ lines) (T able 2 , bel ow). This pattern of expression is consistent with that reported previously for the TRAP promoter in transgenic mice (Boyce 1995) and differs from the nearly ubiquitous expression of endogenous c-src.

The four TRAPsrc ${ }^{\mathrm{WT}}$ lines (A-D) were crossed to src $H-$ mice, and progeny were interbred to generate src $-1-$ TRAPsrc ${ }^{\mathrm{WT}}$ mice and evaluate the effects of the TRA Psrc $^{\mathrm{WT}}$ transgene on the src -1 - phenotype. Because functional osteoclasts are required to resorb a channel in jaw bones through which incisor teeth pass, one of the most obvious aspects of the src- - -phenotype is a lack of tooth eruption (Soriano et al. 1991). Expression of the TRAPsrc $^{\mathrm{WT}}$ transgene in all four lines restored normal tooth eruption in src $-1-$ mice (Table 1 ), as illustrated radiographically in Figure 2a. Microscopic examination of long bones revealed that the transgene had restored normal bone histology (Fig. 2b) and volume (Fig. 3). Furthermore, expression of the transgene al so rescued osteoclast morphology (Fig. 2c); osteoclasts in bone sections from rescued mice display normal ruffled borders.

The TRAPsrc ${ }^{W T}$ transgenic lines showed no major deleterious effects of expressing the chicken c-src CDNA. The rescued mice, including those from line $C$, in which transgene expression is limited to osteoclasts and intestine, were grossly indistinguishable from their wild-type and heterozygous littermates. The src $-1-T$ RAPsrcWT mice appeared healthy, with no unexpected deaths up to 1.5 years of age, and both sexes were fully fertile. In
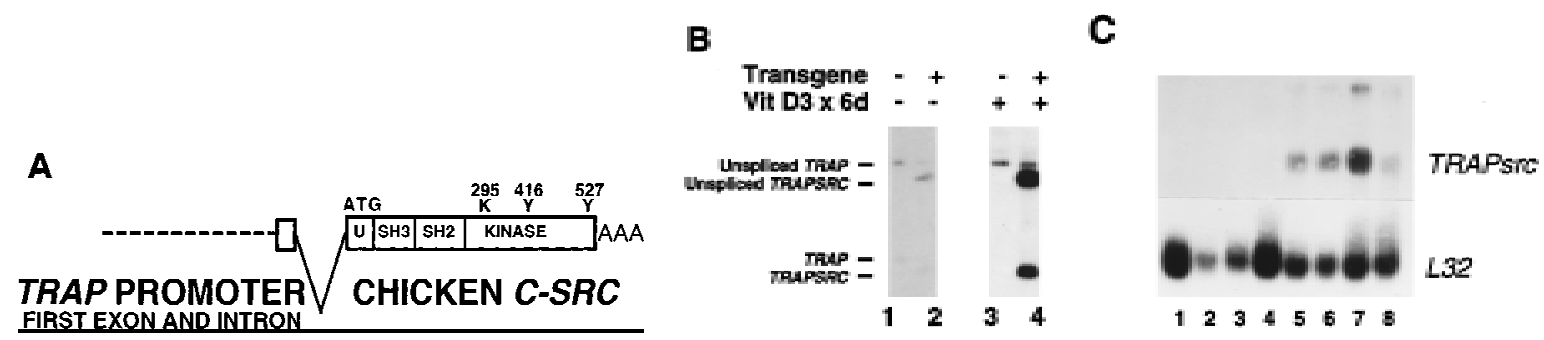

Figure 1. (A) Structure of the TRAPsrc transgene. The TRAP promoter, first exon, and intron were fused to the ATG of the chicken c-src cDN A. Encoded amino-acids important for activation of Src or mutated in transgenic constructs are indicated above the drawing. (U) Unique region; (SH2) Src homology 2 region; (SH3) Src homology 3. (B) Expression of the TRA Psrc transgene in cultured osteoclasts from transgenic mice. RN A samples isolated from fresh bone marrow and from bone marrow cultured in the presence of $10^{-9} \mathrm{M}$ Vitamin D3 (Takahashi et al. 1988) were analyzed by RT-PCR, using primers that generate products extending from the TRAP first exon to both the chicken c-src and the endogenous TRAP-coding sequences. Products were hybridized with a $\mathrm{P}^{32}$-labeled probe that recognizes the TRAPsrc-specific band as well as unspliced TRAP RNA. (Lanes 1,2) Fresh bone marrow; (lanes 3,4) bone marrow cultured in the presense of $10^{-9} \mathrm{M}$ Vitamin D3. (Lanes 1,3) $\mathrm{N}$ on-transgenic mice. (C) $\mathrm{N}$ orthern analysis of RN A derived from tissues of trangenic line A and C mice. (Lanes 1-7) Line A (Lane 1) Testes; (Iane 2) brain; (lane 3) heart; (Iane 4) spleen; (lane 5) kidney; (lane 6) liver; (lane 7) small intestine; (Lane 8) line $C$ small intestine. (top) The filter was hybridized with a probe consisting of the first 200 bp of the chicken c-src gene; (bottom) the hybridized to a probe for RNA encoding the L32 ribosomal protein. 
Table 1. Tooth eruption in src gene-targeted and transgenic mice

\begin{tabular}{|c|c|c|c|}
\hline Mouse line & $\begin{array}{c}\text { C-src } \\
\text { genotype }\end{array}$ & Transgene & $\begin{array}{c}\text { Percent } \\
\text { tooth eruption }\end{array}$ \\
\hline & $H+,+1-$ & none & 100 \\
\hline & $-1-$ & none & $<1(n>100)$ \\
\hline A & $-1-$ & TRAPsrc $^{\mathrm{wt}}$ & $100(n>100)$ \\
\hline$B-D$ & $-1-$ & TRAPsrc $^{\text {wt }}$ & 100 ( $n>12 /$ line $)$ \\
\hline G & $-1-$ & TRAPscr ${ }^{\text {416F }}$ & $100(n=23)$ \\
\hline $\mathrm{H}$ & $-1-$ & TRAPscr $^{\text {Y416F }}$ & $100(n=10)$ \\
\hline J & $-1-$ & TRAPscr K295M & $96(n=22)$ \\
\hline $\mathrm{N}$ & $-1-$ & TRAPscr ${ }^{\mathrm{K} 295 \mathrm{M}}$ & $73(n=18)$ \\
\hline
\end{tabular}

contrast, src $-1-$ mice in this genetic background had greatly reduced fertility and high rates of morbidity and mortality, as described previously, with $\sim 1 / 3$ of animals dying between 3-6 weeks of age and continual loss thereafter (Soriano et al. 1991). Therefore, despite a relatively limited pattern of expression of this typically widely expressed gene, we have obtained full complementation of both the osteopetrosis and the increased morbidity of src- - -mice. Abnormalities have been reported in several cell types, including neurons and fibroblasts, cultured from src $-1-$ mice (Ignel zi et al. 1994; Kaplan et al. 1995). However, our data suggest that the major cause of increased morbi dity in src $-1-$ mice results di rectly from osteopetrosis and support earlier evidence that src deficiency in osteoclasts is responsi ble for the bone pathology.

Kinase-defective mutants of Src rescue the src- 1 -phenotype

The ability of the wild-type transgene to rescue mice from osteopetrosis facilitates a genetic approach to the study of Src in osteoclasts in vivo, a physiologically relevant setting in which the lack of Src protein produces marked phenotypic effects. We have taken advantage of this system to investigate the requirement for the various structural regions of the Src protein in the osteoclast by generating src $-1-$ mice that express mutant versions of Src that affect kinase activity.

We first generated mice expressing $\mathrm{src}^{\mathrm{Y} 416 \mathrm{~F}}$, an allele that reduces full activation of the kinase several fold by changing the tyrosine of the major autophosphorylation site in pp60 ${ }^{\text {src }}$ to phenylalanine (Kmiecik and Shalloway 1987; Piwnica-Worms et al. 1987). Like wild-type src, this mutant also fully restored tooth eruption in two independent transgenic lines (lines $G$ and $H$ ) when expressed as a transgene (TRAPsrc ${ }^{\mathrm{Y} 16 \mathrm{~F}}$ ). X-ray and histological analyses confirmed that the $\mathrm{src}^{\mathrm{Y} 416 \mathrm{~F}}$ mutant transgene produced near normal bone histology and volumes in src $-1-$ mice (Figs. 2a,b and 3). Furthermore, like their wild-type-rescued counterparts, the src-1 -TRAPsrc ${ }^{\text {416F }}$ mice were fully fertile and have remained heal thy up to 9 months of age.

As a more stringent test of the requirement for kinase activity, we examined the effects of expression of
$\mathrm{src}^{\mathrm{K} 295 \mathrm{M}}$, an allele that encodes a protein deficient in kinase activity because the ATP-phosphotransferase site of pp60 ${ }^{\text {src }}$ is disrupted (Kamps and Sefton 1986). Surprisingly, expression of this allele under the control of the TRAP promoter also restored tooth eruption in the src $-1-$ background. One transgenic line expressing the $\mathrm{src}^{\mathrm{K} 295 \mathrm{M}}$ mutant (line J) complemented the src-l-phenotype almost completely. A second line (line N) restored tooth eruption in the majority $(73 \%)$ of src-lmice (Table 1). Although the src-l-TRAPsrc ${ }^{\mathrm{K} 295 \mathrm{M}}$ rescued mice were often smal ler than their wild-type littermates, we have not observed increased mortality in the rescued animals up to 9 months of age. However, these mice are less fertile and exhibit more restricted patterns of expression of the transgene than the src $-1-$ TRAPsrc ${ }^{\mathrm{WT}}$ transgenic mice (Table 2). As with the Y 416F and wildtype transgenes, we observed no adverse effects of expression of the K295M mutant in src+/ + and heterozygote backgrounds.

Expression of the K295M mutant protein, with its se verely impaired kinase activity, was associated with more variable effects on bone histology and density than was expression of the Y416F mutant (Fig. 2, bottom two panels). N evertheless, bone volumes were improved significantly relative to src $-1-$ mice $(P<0.05$; Fig. 3 ); in some of the mice (Fig. 2, bottom panel), the bones appeared entirely normal, indicating complete rescue of the bone phenotype. Osteocl asts from mice rescued with either the $\operatorname{src}^{\mathrm{K} 295 \mathrm{M}}$ or the $\mathrm{src}^{\mathrm{Y} 416 \mathrm{~F}}$ transgenes formed ruffled borders, although these structures were present in fewer osteoclasts in animals rescued by the $\mathrm{Src}^{\mathrm{K} 295 \mathrm{M}}$ mutant compared with $\mathrm{Src}^{\mathrm{Y} 416}$ (Fig. 2c). We also did not observe an increase in the number of osteoclasts in these mice, compared with wild-type animals, unlike the increase observed in src $-1-$ mice.

Functional capabilities of the kinase-inactive rescued osteoclasts

To test the functional capabilities of osteoclasts in src $-1-$ mice expressing the TRAPsrc ${ }^{\mathrm{K} 295 \mathrm{M}}$ transgene, we chal lenged these animals with interleukin-1 (IL-1), a potent stimulator of bone resorption that typically causes a transient increase in whole-blood-ionized calcium and an increase in osteoclast number in normal mice after several days treatment (Boyce et al. 1989). Osteoclasts from src $-1-$ mice treated with IL-1 increase in number, but do not resorb bone, and no change is seen in blood cal cium levels (Boyce et al. 1992). In contrast, animals rescued by the TRAPsrc ${ }^{\mathrm{K} 295 \mathrm{M}}$ allele responded to a challenge of IL-1 with an increase in whole blood ionized cal ci um, indi cative of appropriately activated osteoclasts ( $T$ able 3 ) and a general ized increase in bone resorption in vivo.

\section{src -1 - osteoclasts have al tered cell morphology}

Despite complete or almost complete rescue of the osteopetrosis, osteoclasts in the src $-1-$ TRA Psrc ${ }^{\mathrm{K} 295 \mathrm{M}}$ mice had an elongated rather than a rounded morphology and 
Figure 2. Radiographic and histological analysis of mice. (A) X-rays, lateral view. (B) Histological sections of tibia, low power $(4 \times$ magnification). Sections were stained both with hematoxylin and eosin and for TRAP activity. (C) Histological sections, TRAPstained osteoclasts in bone, high power (100X, note lacy ruffled border structures at the interface between osteocl asts and bone surface.) Genotypes of mice are indicated. Two examples of bones from src $-1-$ mice rescued by the K295M transgene (TRAPsrc ${ }^{\mathrm{K} 295 \mathrm{M}}$ ) are shown to demonstrate the variability in phenotype. The bottom sample from a src-l -TRAPsrc ${ }^{\mathrm{K} 295 \mathrm{M}}$ mouse is derived from the calvarium after treatment with IL-1 and is stained with hematoxylin and eosin only.

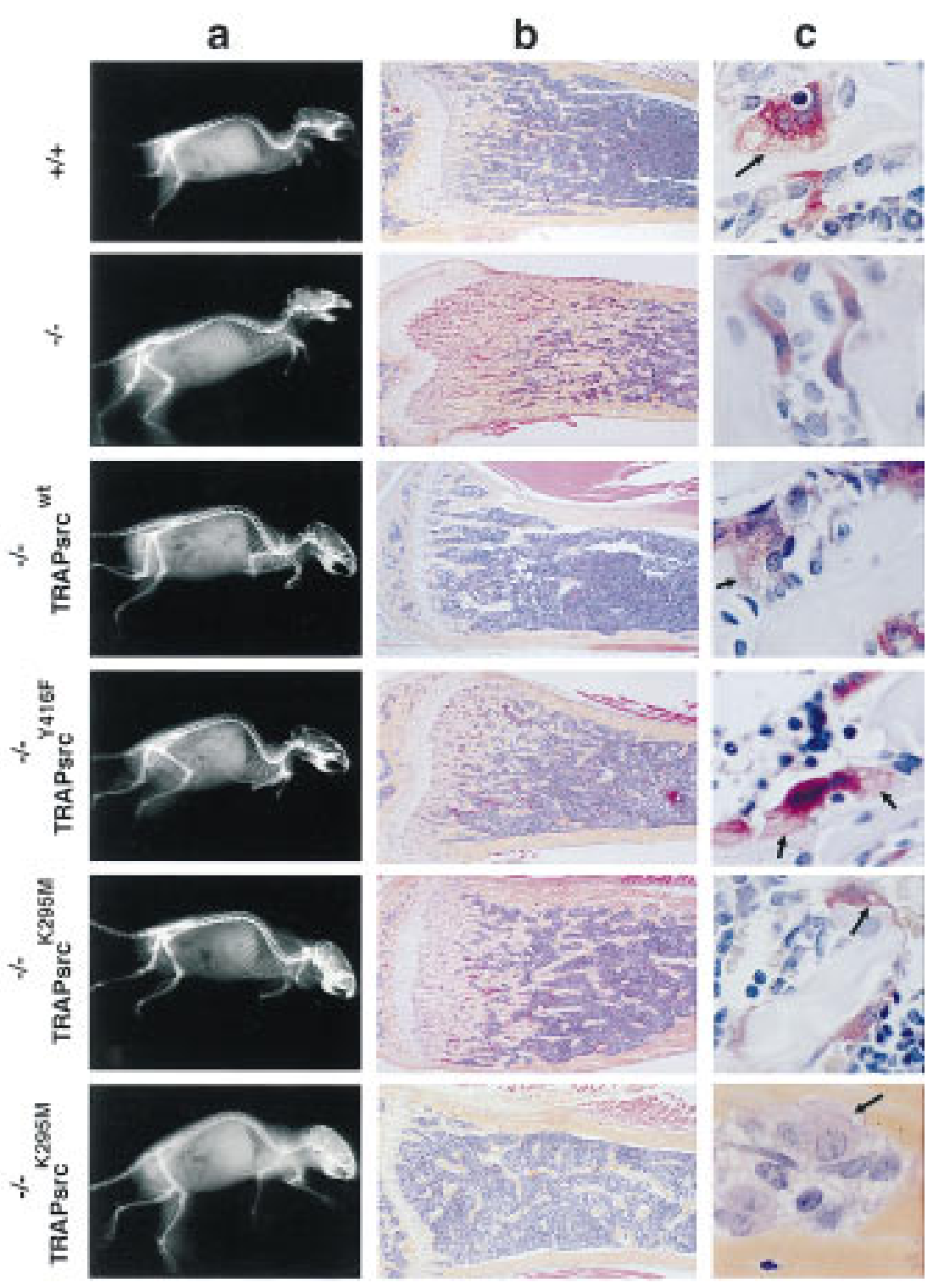

as such appeared more similar to osteoclasts in src-lmice (Fig. 2). To explore further differences in the morphology of these cells, we examined osteoclasts differentiated from bone marrow cells in culture. Osteoclasts differentiated from bone marrow cells cultured from src $-1-$ mice in the presence of 1,25 D3 appear markedly different from osteoclasts derived from the bone marrow of src $H+$ mice (Fig. 4A). In particular, after they form by fusion of TRAP-positive mononuclear precursors, these cells fail to assume the typical rounded appearance of wild-type osteoclasts and have an elongated appearance, somewhat resembling cells seen in bone sections from these mice.

To examine these differences further, we stained cells with rhodamine-phalloidin to highlight F-actin filaments and examined them by confocal mi croscopy. N ormal osteoclasts adhere to plastic through a specialized structure called the podosome, found on motile cells like macrophages as well as on fibroblasts transformed by v-src. (M archisio et al. 1984). These adhesive structures are represented by dot-like aggregations of actin, which cluster in a ring around the periphery of wild-type osteoclasts plated on plastic (Lakkakorpi and Vaanenen 1991; Teti et al. 1991). src-l-osteoclasts, in contrast, have a markedly different distribution of actin, with no peripheral podosome arrangement; the actin organization in these cells more closely resembles the stress fibers of fi broblasts (N eff et al. 1996). These observations suggest that Src has a fundamental role in organizing the actin cytoskeleton of osteoclasts.

Examination of osteoclasts from src $-1-$ mice rescued with a wild-type transgene demonstrated that actin is organized normally, providing further evidence of full rescue of the morphology of these cells (Fig. 4B). Osteoclasts from mice rescued with the $Y 416 F$ mutant also exhibited a normal pattern of actin. However, part of 
Table 2. Summary of expression patterns of transgenic mice

\begin{tabular}{lcccccc}
\hline & \multicolumn{7}{c}{ Transgenic line } \\
\cline { 2 - 7 } Tissue & A & B & C & D & J & N \\
\hline Cultured bone marrow & + & + & + & + & + & + \\
Small intestine & + & + & + & + & + & + \\
Liver & + & + & - & + & - & - \\
Kidney & + & + & - & + & - & - \\
Spleen & - & - & - & - & - & - \\
Heart & - & - & - & - & - & - \\
Thymus & - & + & - & - & - & - \\
Brain & - & - & - & - & - & + \\
Muscle & - & - & - & - & - & - \\
Testes & - & - & - & - & - & - \\
Ovary & - & - & - & - & - & - \\
Mammary & - & N.D. & N.D. & N.D. & - & - \\
Lung & - & - & - & - & - & - \\
\hline
\end{tabular}

Expression patterns were examined by Northern blotting, except for cultured osteoclasts, which were analyzed by RT-PCR as in Fig. 1B. Lines A-D express the TRAPsrc ${ }^{W T}$ transgene. Lines J and $\mathrm{N}$ express the TRAPsrc ${ }^{\mathrm{K} 295 \mathrm{M}}$ transgene. (N .D.) $\mathrm{N}$ ot determined.

their actin ring was often diffuse, a feature that has been observed in osteoclasts moving across a surface (Baron et al. 1993). In contrast, many osteocl asts from src $-1-$ mice rescued with the TRAPsrc ${ }^{\mathrm{K} 295 \mathrm{M}}$ transgene appear very similar to src -1 -osteoclasts (Fig. 4B; bottom right). Some src $-1-$ TRA Psrc $^{\mathrm{K} 295 \mathrm{M}}$ osteoclasts did have a more rounded appearance and a peri pheral actin organization. However, the actin pattern in many of these cells was still not consistent with a normal podosome arrangement. Only relatively rare osteoclasts display the normal peripheral actin podosome pattern (Fig. 4B, bottom left), despite the ability of these cells to rescue bone resorption in mice. These differences may result from variation in the degree of rescue of the osteoclasts from these

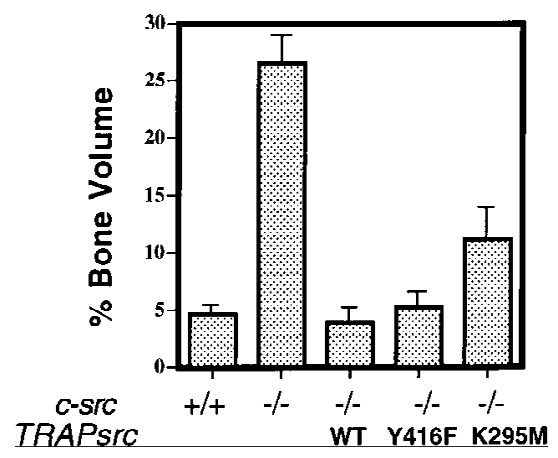

Figure 3. Histomorphometric analysis of rescued mice. Genotype of mice indicated on $x$ axis. Percentage bone volume [amount of bone matrix as a percentage of the cancellous bone (Boyce et al. 1992)] is indicated on the y axis. A minimum of four samples were examined for each transgene. Histology was performed on samples from at least two transgenic lines for each construct, except for the TRA Psrc ${ }^{\text {Y416F }}$ rescued mice (histomorphometry was performed on line G only).
Table 3. TRAPsrc ${ }^{\mathrm{K} 295 \mathrm{M}}$ restores osteoclast bone resorption in response to IL-1

\begin{tabular}{lccc}
\hline & \multicolumn{3}{c}{ Blood Ca $^{2+}(\mathrm{mmole} /$ liter $)$} \\
\cline { 2 - 4 } Genotype & pre-IL-1 & post IL-1 & difference \\
\hline Wild type & $1.25 \pm 0.03$ & $1.36 \pm 0.05$ & 0.11 \\
src-1-TRAPsrc ${ }^{\mathrm{K} 295 \mathrm{M}}$ & $1.25 \pm 0.02$ & $1.33 \pm 0.03$ & 0.08 \\
Wild type & $1.28 \pm 0.01$ & $1.44 \pm 0.03$ & 0.16 \\
src-1- & $1.29 \pm 0.02$ & $1.28 \pm 0.01$ & -0.01 \\
\hline
\end{tabular}

Mice (three to five per group) were treated with IL-1 four times daily for 3 days. Whole Blood $\mathrm{Ca}^{2+}$ was measured $2 \mathrm{hr}$ after the last injection. $\mathrm{Ca}^{2+}$ levels in src-1-animals post-IL-1 treatment were statistically lower than those in the wild-type mice $(\mathrm{P}<$ 0.01 ), whereas $\mathrm{Ca}^{2+}$ levels in the src $-1-T R A P s c^{\mathrm{K} 295 \mathrm{M}}$ resued mice were not statistically different than those of wild-type mice $(P>0.25)$. Results from two different experiments are shown (Boyce et al. 1992).

mice. But, overall our results suggest that, whereas expression of the K295M mutant permits bone resorption in vivo, it does not fully restore osteocl asts morphology, and only restores partial cytoskel eton organization in osteoclasts plated on glass.

Biochemical analysis of osteoclasts derived from kinase-defective Src mice

Given the surprising finding that a kinase-defective allele rescues Src-deficient animals from osteopetrosis, we confirmed that the point mutations in the kinase-defective src allele had not reverted to normal sequence by examining both DNA and protein from the transgenic mice. DNA from TRAP-src transgenic mice was amplified by PCR and the expected products were detected by allele-specific hybridization with oligonucleotides demonstrating retention of the mutations (data not shown). To examine the enzymatic activity of the Src proteins, in vitro kinase assays were performed on immunoprecipitated $\mathrm{pp} 60^{\mathrm{Src}}$ from osteoclasts cultures derived from the bone marrow of $\mathrm{srC}+1+, \operatorname{src}-1-$, src $-1-T$ RAP- $\mathrm{src}^{\mathrm{K} 295 \mathrm{M}}$ and src-l-TRA Psrc ${ }^{\text {Y16F }}$ mice. Despite similar levels of protein relative to endogenous Src (within two-to fourfold), no kinase activity above background was detected with the $\mathrm{Src}^{\mathrm{K} 295 \mathrm{M}}$ mutant on the exogenous substrate, enolase (Fig. 5A), whereas the $\mathrm{Src}^{\Upsilon}{ }^{416 \mathrm{~F}}$ mutant displayed reduced kinase activity relative to that of wild-type Src.

We then examined patterns of total cellular tyrosine phosphorylation in osteoclasts cultured from mice rescued by the kinase-inactive $\mathrm{src}^{\mathrm{K} 295 \mathrm{M}}$ allele. Basal levels of phosphotyrosine were consistently lower in osteoclasts derived from src $-1-$ bone marrow than in cells derived from wild-type mice (Fig. 5B). However, the overall extent of tyrosine phosphorylation was restored in osteoclasts derived from mice rescued by the TRA Psrc ${ }^{\mathrm{K} 295 \mathrm{M}}$ transgene. Hunter and colleagues have detected an extremely low level of residual kinase activity of $\mathrm{Src}^{\mathrm{K} 295 \mathrm{M}}$ when overexpressed by baculovirus $(\varangle 0003 \%$ of wild-type levels) (Broome 1996). We think it 


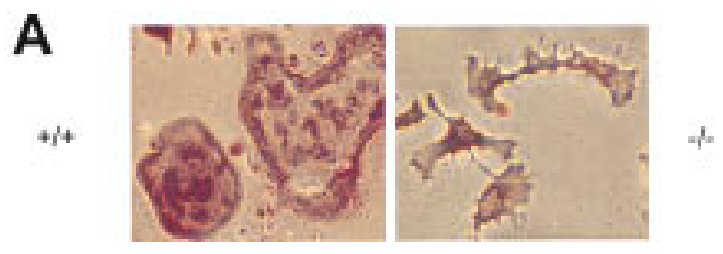

B

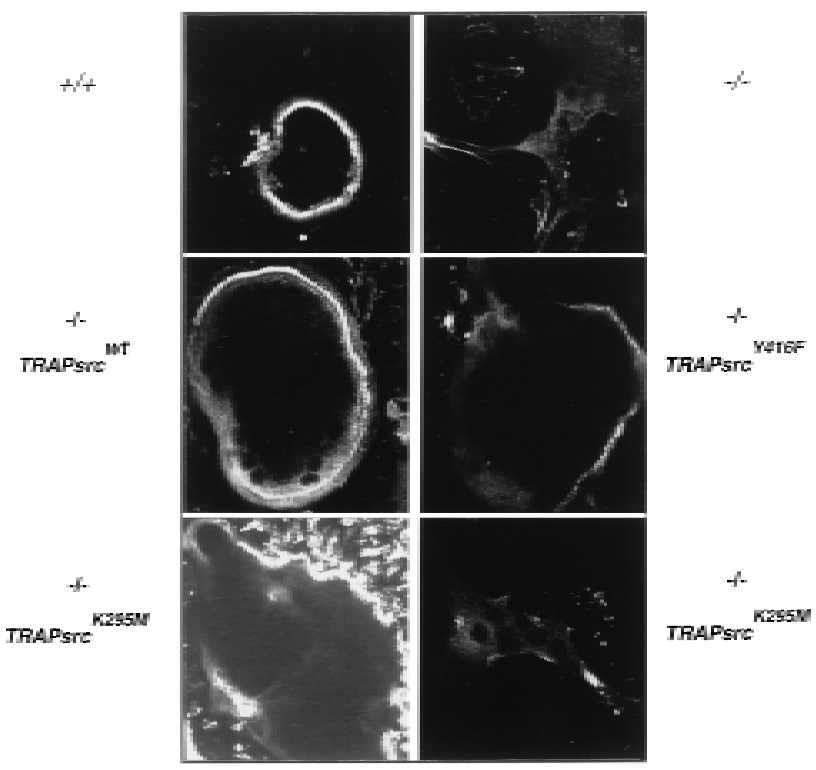

Figure 4. Rescue of abnormal morphology of src -1 - osteoclasts by expression of TRAPsrc transgenes. (A) M orphology of src -1 - osteoclasts. Osteoclasts were differentiated on plastic, partially purified, and stained for TRAP activity. (B) Actin organization of osteoclasts expressing TRAPsrc transgenes. Osteoclasts were stained with Rhodamine-phalloidin and examined by confocal microscopy. Genotypes of Osteoclasts are indicated. $\mathrm{N}$ ote lack of peripheral actin ring in src $-1-$ osteoclasts.

unlikely that this small amount of kinase activity could account for the increase in cellular tyrosine phosphoryIation we observe, particularly because the amount of Src ${ }^{\text {K295M }}$ protein present in cultured osteocl asts is lower (two to fivefold) than that of endogenous Src in cells derived from normal mice. Because the intrinsic kinase activity of $\mathrm{Src}^{\mathrm{K} 295 \mathrm{M}}$ is defective and kinase activity is undectectable in osteoclasts from src-/-TRA Psrc ${ }^{\text {K295M }}$ mice (Fig. 5A), the increase in tyrosine phosphorylation we observe suggests that $\mathrm{Src}^{\mathrm{K} 295 \mathrm{M}}$ may function in part by activating or recruiting other tyrosine kinases.

\section{Discussion}

Transgenic rescue of src $-1-$ mice

Despite the ubiquitous expression of c-src, mice deficient in src demonstrate only one major phenotypemoderately severe osteopetrosis, with resulting high rates of morbidity and mortality attributable to an in- trinsic defect in osteoclasts. We have now generated transgenic mice that express c-src in limited cell lineages. These mice support earlier conclusions that the defect in osteoclasts alone accounts for the src $-1-$ phenotype and that osteopetrosis is specifically due to the lack of Src expression in these cells. The availability of heal thy, fertile src $-1-$ TRAPsrc mice with limited patterns of src expression should now facilitate the study of Src deficiency in other tissues, as well as the generation of src -1 -cell lines, and the breeding of Src deficiency into a number of genetic backgrounds. In particular, these mice may be useful for the generation of mice and cell lines containing loss-of-function mutations in multiple src family members and for the study of the actions of mutant forms of Src family proteins in signaling pathways.

Kinase-independent functions of Src

In this paper, we have used the TRAPsrc transgenic system to examine the functional capabilities of mutant versions of Src. Our observation that kinase-defective versions of Src protect src $-1-$ mice against osteopetrosis indicates that the intrinsic kinase activity of Src itself is not required for certain critical functions of Src in osteoclasts. These results suggest that there are essential Src

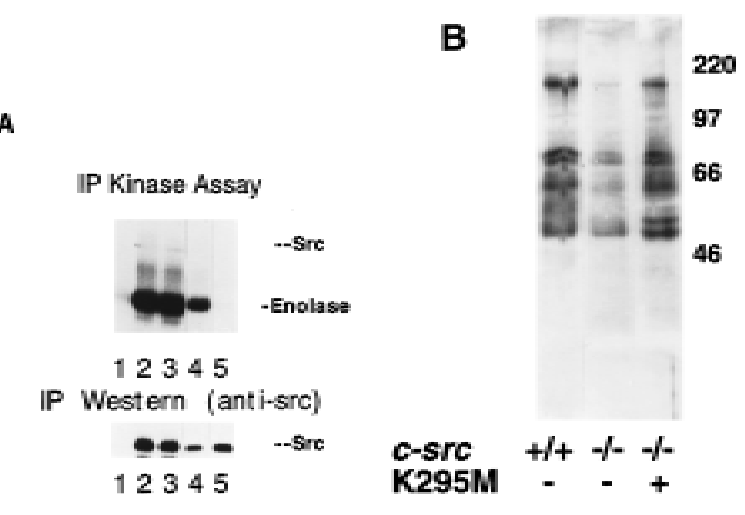

Figure 5. Osteoclasts from mice rescued with the TRA Psrc ${ }^{\mathrm{K} 295 \mathrm{M}}$ transgene lack detectable Src kinase activity but have normal levels of tyrosine phosphorylation. (A) In vitro kinase assays. Osteoclasts derived from bone marrow were lysed in RIPA buffer, and extracts were normalized for both protein concentration (Biorad) and TRAP enzymatic activity (Sigma); after immunoprecipitation with anti-Src monoclonal 327 (Calbiochem), in vitro kinase assays with the exogenous substrate enolase were performed as described previously (Kaplan et al. 1995). One-half of each immunoprecipitate was analyzed by Western blotting probing with the Src2 antisera (Santa Cruz). (Lane 1) src-1-; (lane 2) src + +; (lane 3) src-1-TRAPsrc ${ }^{W T}$ line A; (lane 4) src-l-TRAPsrc ${ }^{\mathrm{WT}}$ line C; (lane 5) src-1-TRA Psrc ${ }^{\mathrm{K} 295 \mathrm{M}}$. (B) Tyrosine-phosphorylated proteins from cultured osteoclasts from wild-type src- - - and kinase-defective rescued mice. Protein extracts from cultured osteocl asts were normal ized for both protein concentration (Bio-Rad) and TRAP enzymatic activity (Sigma), and analyzed with the 4G 10, anti-phosphotyrosine antibody $(\mathrm{UBI})$. Lanes are derived from the same exposure of a single gel. 
signal ing pathways in osteoclasts that are independent of Src kinase activity, a finding that contrasts with previous observations that certain signaling pathways in cultured cells appear to require Src kinase activity. For example, overexpression of the same kinase-defective mutant of Src used in our studies (K295M) interferes with growth factor signaling in isolated fibroblasts (T waml eyStein et al. 1993; Broome and Hunter 1996). Kinase-negative al leles al so adversely affect stress-activation of Jun kinase and hypoxia-induced expression of vascular endothelial growth factor (VEGF) (Devary et al. 1992; Mukhopadhyay et al. 1995), whereas other kinase-defective Src family members expressed previously in transgenic animals have acted in a dominant-negative manner (Cooke et al. 1991; Levin et al. 1993). Given the dominant-negative properties of overexpression of the K295M mutant in multiple pathways, it is remarkable that not only do we not see adverse effects of expression of this mutant in wild-type and heterozygote animals, but the same mutant rescues the src $-1-$ phenotype. It is yet another indication that the osteoclast may have distinctive signaling pathways that require the Src protein.

The global decrease in tyrosine phosphorylation we observe in the osteoclasts from src -1 -mice suggests that Src may be requi red for proper phosphorylation of a large number of proteins involved in many cellular functions. This observation is similar to the decrease in tyrosine phosphorylation found in the brains of fyn $-1-$ mice (Grant et al. 1995) and supports roles for Src family kinases in multiple signaling pathways within a given cell. Our present results suggest further that at least some of these pathways may be independent of Src's own intrinsic kinase activity.

$\mathrm{N}$ ot all pathways involving Src may require kinase activity. Activation and cross-linking of integrin receptors is associated with a transient increase in Src kinase activity and translocation of Src to the focal adhesion complex where Src interacts with and phosphorylates the focal adhesion kinase (FAK) (Schal ler et al. 1994; Schaller and Parsons 1994; Schlaepfer et al. 1994; Clark and Brugge 1995). Kaplan et al . (1995) have demonstrated previously that cultured fi broblasts from src $-1-$ mice havea defect in cell spreading when plated on fibronectin-a defect presumably related to the activation of Src by integrin-mediated signaling. Complementation of this defect may not require the kinase activity of Src, as cell spreading is restored by re-addition of alleles encoding either wild-type or kinase-defective Src. Similarly, we and others have shown that the Src-dependent tyrosine phosphorylation of pp130 cas in fibroblasts in response to fibronectin binding (Vuori et al. 1996) does not require intrinsic Src kinase activity (Schlaepfer et al. 1997; P. Schwartzberg, unpubl.). Our results in transgenic mice now show that such kinase-independent signaling pathways for Src are physiologically important for the function of osteoclasts in intact animals and, furthermore, suggest that some of the defects in these cells may be related to such kinase-independent pathways as integrin signaling.

Therefore, $\mathrm{Src}^{\mathrm{K} 295 \mathrm{M}}$ may provide signal ing function in some pathways and act in other pathways as a domi nantnegative bl ock to signal transduction. These differing actions of Src may in part account for the variability we observe in the phenotype of the rescued mice. In addition to beneficial effects of the transgene on osteoclast function, there may be detrimental effects; for example, high levels of expression of the $\mathrm{src}^{\mathrm{K} 295 \mathrm{M}}$ allele might block kinase-dependent signaling pathways as observed in other cell types and therefore prevent full rescue of the osteopetrosis. In cultured osteoclasts from these transgenic mice, our average levels of expression are similar to that of endogenous Src, potentially limiting adverse effects from overexpression of the kinase-dead allele. Alternatively, the mixed genetic background of the rescued mice (129/Sv/Ev $\times$ C57BL6/J $\times$ FVB/N) may partially account for the variation observed. Additional backcrossing to pure genetic strains should help resolve these issues.

\section{Parallels with other tyrosine kinases}

The related Src family member, Lck, has also been thought to have both kinase-dependent and kinase-independent signaling pathways in an isol ated T Iymphocyte cell line (Xu and Littman 1993). In the studies of Lck, however, kinase-independent functions were demonstrated with molecules fused to the upstream effector CD 4 in cells that contained endogenous Lck. Recent evidence suggests that endogenous Lck may be required for the signaling by kinase-inactive Lck fusion proteins and that a multimeric complex may be involved in this pathway (Lee-Fruman et al. 1996). In src- $-1-$ mice rescued with the TRAPsrc ${ }^{\mathrm{K} 295 \mathrm{M}}$ transgene, there is no endogenous Src. Furthermore, the kinase-independent rescue that we observe in osteocl asts was achieved without additional alteration of the Src molecule, suggesting that the kinase-inactive Src molecule itself can provide function. Our results more closely resemble the partial rescue observed with kinase-inactive D-abl of the Dab-Iphenotype in Drosophila melanogaster (Henkemeyer et al. 1990). However, unlike our observations with c-src, a transgene-encoding kinase-inactive $c$-abl does not complement the abl- - -phenotype in mice (Hardin et al . 1996).

\section{Src functions in the osteoclast}

Osteoclasts from src- - - mice lack ruffled borders and normal organization of the actin cytoskeleton, and they do not resorb bone, but the biochemical and physiological defects that account for this complex phenotype remain unclear. Our findings with the TRAP-src ${ }^{\mathrm{K} 295 \mathrm{M}}$ mice suggest that Src may have multi ple roles within the osteoclast. Proper intracel lul ar transport, exocytosis, cell polarization, adhesion, migration, and cytoskel etal organization are all candidates for functions that might be impaired by defective signaling in src $-1-$ cells. It is clear that at least one pathway that requires Src function is that involved in cytoskeletal organization ( $\mathrm{N}$ eff et al. 1996). 
Restoration of osteoclast function by kinase-defective versions of Src suggests that at least some critical functions of Src in these cells may be related to other properties, such as the protein interaction and localization functions of the $\mathrm{SH} 2$ and $\mathrm{SH} 3$ domains. Complementation of the adhesion defect in src $-1-$ fibroblasts by a truncated version of Src requires intact $\mathrm{SH} 2$ and $\mathrm{SH} 3$ domains (Kaplan et al. 1995). These domains have been demonstrated to be important both for interactions with other molecules and for proper redistribution of Src protein mutants to focal adhesions on activation in fibroblasts (Pawson and Gish 1992; Kaplan et al. 1994). Furthermore, the increase in total tyrosine phosphorylation in osteoclasts rescued by kinase-inactive Src suggests that a critical function of Src may be in part to act as an adaptor mol ecule that recruits or activates other tyrosine kinases and their substrates. Particular targets for activation by Src include FAK and the related kinase Pyk 2 in the osteoclast (Lev et al. 1995). These kinases may, in turn, phosphorylate downstream targets crucial for osteoclast function, such as the recently described $\mathrm{Cbl}$ molecule (T anaka et al . 1996) or integrin-sti mulated substrates, such as Cas (Vuori et al. 1996). It is interesting to note that integrin engagement is required for proper bone-resorption by osteoclasts (Davies et al . 1989); therefore, integrin-mediated signaling may be one pathway that is abnormal in src-l-osteoclasts. Elucidation of such pathways may hel p delineate the functional abnormal ities in osteocl asts and in other cells that lack the Src protein.

\section{Materials and methods}

Plasmid construction

The plasmid pKB5 containing the TRAP promoter was a kind gift from Drs. S. Reddy and G.D. Roodman (Reddy et al. 1995). The TRAPsrc plasmid was contructed by fusing the src ATG to the ATG of TRAP by PCR using primers TRAP1 (CCACCTCCATGGTAGTGCC), Srcl (GTCTTGTTGGGGGTCTGCG), TRAPSRC1 (CCCTCTCTTCCTCCACAGATGGGGAGCAG CAAGAGCA and SRCTRAP (TGCTCTTGCTGCTCCCCATC TGTGAGGAAGAGAGGG). A 148-bp fragment was cloned to the Sph1 site of the TRAP promoter and the Nael site of the chicken c-src gene using a three-fragment ligation. A BamHINotl fragment containing the polyA site from plasmid pGKTKpolA was introduced into the Bglll to $\mathrm{N}$ otl site of the TRAPsrc construct. The K295M mutant and Y416F mutant were rederived by PCR and subcloned into the TRAPsrc construct.

\section{Transgenic mice}

Transgenic mice were generated by standard pronuclear injection methods into FVB/N strain. Tail DNA was isolated and mice genotyped by PCR using primers TRAP1, SRC 1 , and TRAP2 (GTGGAATGGGGCATTGGGG) for the TRAPsrc alleles. $F_{1}$ mice were bred to srct/-mice $(129 / \mathrm{Sv} / \mathrm{Ev} \times \mathrm{C} 57 \mathrm{BI} / \mathrm{J})$ generously provided by Dr. P. Soriano. Primers used for genotyping the endogenous c-src allele were SrcF (CAGCAACAAGAGCAAGCCCAAGGACG), NeoS (CAGTCATAGCCGAATAGCCTCTCCACC), NSrC3 (GGGAGGTGACGGTGT CCGAGGA). These primers differ from primers published previously to eliminate spurious amplification from the TRAPsrc allele. Products were visualized on a $10 \%$ polyacrylamide TBE gel.

\section{Histology}

Bones (calvaria, fore- and hindlimbs, and lumbar vertebrae) were fixed in $10 \%$ buffered formalin, decalcified in 14\% EDTA, and embedded in paraffin. The sections were stained both with hematoxylin and eosin and for TRAP activity and the bone volume (amount of bone matrix as a percentage of the cancellous space), and osteoclast numbers (expressed per millimeter of the cancellous bone surface) in the cancellous space of the long bones were measured, as described previously (Boyce et al. 1992). For histology, a minimum of four samples were examined for each transgene. Histology was performed on samples from at least two transgenic lines for each construct except for the TRAPsrc $^{\text {Y416F }}$ rescued mice where histomorphometry was performed on line $\mathrm{G}$ only.

\section{II-1 treatment}

Human recombinant IL-1a (a gift from Dr. R. Chizzonite, Hoffman LaRoche, Nutley, NJ) $(0.2 \mu \mathrm{g}$ in $10 \mu \mathrm{l})$ was injected four times daily for 3 days into the loose subcutaneous tissue overlying the calvaria of the mice. Whole-blood-ionized cal cium was measured in retro-orbital venous samples using a $\mathrm{Ciba}$ Corning 634 ISE Ca+t/pH analyzer (M edfield, MA) before and $2 \mathrm{hr}$ after the last IL-1a injection. A minimum of three mice per group were examined. Results from the different sets of animals were compared using unpaired (two-tailed) student t-tests.

\section{Cell culture}

Osteoclasts were generated either by plating bone marrow directly in the presence of vitamin D3 $\left(10^{-9} \mathrm{M}\right)$ for 7 days (Takahashi et al. 1988a) or by plating with primary calvarial osteoblasts derived from src-1-mice for 5-7 days (Takahashi et al. 1988b). N ewborn litters of src $+1-$ intercrosses were genotyped by PCR at birth and calvaria cells from the src -1 -progeny were isolated as described (Takahashi et al. 1988b).

\section{RNA analysis}

Total cellular RNA was isolated using RN azol (Tel-test) from osteoclasts derived from bone marrow cultured in the presence of vitamin D3. RNA was reverse-transcribed (CDNA cycle Kit, Invitrogen) and transgene-specific primers, TRAP4 (TGCAGCC TCTCTGACCACCTGTGC) and SRC1, were used to amplify a fragment extending from the TRAP first exon to the chicken c-src-coding region. The TRAP1 primer was included in the same reaction to amplify a control TRAP-specific band. Products from amplification were visualized on a $10 \%$ polyacrylamide TBE gel and stained with ethidium bromide. The gel was transferred to Zetaprobe membrane (Bio-Rad) at 0.4 amps in $0.5 \times \mathrm{TBE}$, fixed to the membrane with UV and hybridized with the $\mathrm{P}^{32}$-label ed kinased ol igonucl eotide probe TRAPSRC 1 . This probe recognizes the TRA Psrc-specific band as well as unspliced TRAP RNA. For Northern analysis, $30 \mu \mathrm{g}$ of total RNA was analyzed on $1.2 \%$ agarose formal dehyde gel s, transferred to $\mathrm{Hy}-$ bond-N and hybridized to a 200-bp probe corresponding to the first $200 \mathrm{bp}$ of coding sequence of chicken c-src. Filters were stripped and reprobed according to the manufacturer's recommendations. 


\section{Protein}

Osteoclasts from bone marrow cultures were partially purified by washing off the osteoblast layer with PBS. Cells were lysed in RIPA buffer (50 mM HEPES, 1\% dexoycholic acid, 1\% Triton, $0.1 \%$ SDS, $150 \mathrm{~mm} \mathrm{NaCl}, 1 \mathrm{~mm}$ EDTA plus AEBSF, leupeptin, and pepstatin). Extracts were normalized for both protein concentration (Biorad) and by TRAP enzymatic activity (Sigma) assayed at $405 \mathrm{~nm}$. Equival ent amounts of protein were immunoprecipitated with $0.5 \mu \mathrm{g}$ monoclonal 327 (Lipsich et al. 1983) (Oncogene Science) and anti-mouse immunoglobulin-agarose beads (Sigma), washed extensively with RIPA and then washed three times with kinase buffer $(20 \mathrm{~mm}$ Tris at $\mathrm{pH} 7.4,5 \mathrm{~mm}$ $\mathrm{MnCl}_{2}$ ). Reactions were incubated in kinase buffer containing $\sim 2 \mu \mathrm{g}$ acid-denatured enolase for $5 \mathrm{~min}$ at room temperature, as described previously (Kaplan et al. 1995). Half of the immunoprecipitation was analyzed by $10 \%$ SDS-PAGE, transferring to nitrocellulose and blotted using either monoclonal 327 or Src2 sera (Santa Cruz). Phosphotyrosine-containing proteins were examined in normalized whole-cell extracts from osteoclasts purified from co-cultures in which the osteoblast feeder layer was removed completely by careful washing with PBS. Under these conditions, the majority of remaining cells were multinucleated osteoclasts, as determined by light microscopy. Only highly purified cultures of osteoclasts were used in these experiments, and under these conditions, there was a good correlation be tween protein levels and TRAP enzymatic activity. After electrophoresis and blotting of cell extracts, phosphotyrosine-containing proteins were detected with the $4 \mathrm{G} 10$ anit-phosphotyrosine-monoclonal antibody ( $\mathrm{UBI})$.

\section{Immunofluorescence}

Osteoclasts derived from the coculture of bone marrow cells and osteoblasts were grown on serum-coated coverslips, partially purified and fixed with $10 \%$ formal in for $10 \mathrm{~min}$ at room temperature. Cells were either stained for TRAP enzymatic activity or dehydrated with acetone for $2 \mathrm{~min}$, then stained with Rhodamine-phalloidin (Molecular Probes) according to the manufacturer's recommendation. Cells were visual ized by confocal laser scanning microsopy (emission wavelength $568 \mathrm{~nm}$ ) using a Biorad MRC 1024.

\section{Acknowledgments}

We thank Drs. G.D. Roodman and S. Reddy for the gift of the pK5B plasmid; Dr. R. Devlin for technical advice on culturing osteoclasts; Eric Lee, R. Hunziker, Wendy Hively, and Theresa Hernandez for assistance with transgenic animals; Beryl Story and Arlene Farias for excellent technical assistance with the histology; Drs. A. Kimmel and J. Brugge for critical reading of the manuscript; M.J. Lenardo and P. Robey for helpful discussion and support and Dr. R. Chizzonite, Hoffman LaRoche, for the IL-1. P.L.S. is a Special Fellow of the Leukemia Society of America. This work was supported by grants from the $\mathrm{N}$ ational Institutes of Health to B.F.B. (AR 43510 and DK 45229).

The publication costs of this article were defrayed in part by payment of page charges. This article must therefore be hereby marked "advertisement" in accordance with 18 USC section 1734 solely to indicate this fact.

\section{References}

Baron, R., J.-H. Revesl oot, L. N eff, M. Chakraborty, D. Chatterjee, A. Lomri, and W. Horne. 1993. Cellular and molecular biology of the osteoclast. In Cellular and molecular biology of bone. pp. 445-495. A cademic Press, San Diego California. Boyce, B., T. Yoneda, C. Lowe, P. Soriano, and G. M undy. 1992. Requirement of pp60 ${ }^{\mathrm{c}-\mathrm{src}}$ expression for osteoclasts to form ruffled borders and to resorb bone in mice. J. Clin. Invest. 90: 1622-1627.

Boyce, B.F., K. Wright, S.V. Reddy, B.A. Koop, B. Story, R. Devlin, R.J. Leach, G.D. Roodman, and J.J. Windle. 1995. Targeting simian virus $40 \mathrm{~T}$ antigen to the osteoclast in transgenic mice causes osteoclast tumors and transformation and apoptosis of osteoclasts. Endocrinology 136: 5751-5759.

Boyce, B.F., T.B. A ufdemorte, I.R. Garrett, A.J.P. Yates, and G.R. Mundy. 1989. Effects of interleukin-1 on bone turnover in normal mice. Endocrinology 125: 1142-1150.

Broome, M. 1996. PhD thesis. University of California, San Diego, CA.

Broome, M.A. and T. Hunter. 1996. Requirement for c-Src catalytic activity and the $\mathrm{SH} 3$ domain in Platelet-derived Growth Factor BB and Epiderman Growth Factor mitogenic signalling. J. Biol. Chem. 271: 16798-16806.

Brown, M.T. and J.A. Cooper. 1996. Regulation, substrates, and functions of Src. BBA Rev. Cancer 1287: 121-149.

Clark, E.A. and J.S. Brugge. 1995. Integrins and signal transduction pathways: The road taken. Science 268: 233-239.

Cooke, M.P., K.M. Abraham, K.A. Forbush, and R.M. Perlmutter. 1991. Regulation of T cell receptor signalling by a src family protein-tyrosine kinase (p59 fyn). Cell 65: 281-291.

Davies, J., J. Warwick, N. Totty, R. Philp, M. Helfrich, and M. Horton. 1989. The osteoclast functional antigen, implicated in the regulation of bone resorption, is biochemically related to the vitronectin receptor. J. Cell Biol. 109: 1817-1826.

Devary, Y., A. Gottlieb, T. Smeal, and M. Karin. 1992. The mammalian ultraviolet response is triggered by activation of Src tyrosine kinases. Cell 71: 1081-1091.

Grant, S.G., K.A. Karl, M.A. Kiebler, and E.R. Kandel. 1995. Focal adhesion kinase in the brain: $N$ ovel subcellular localization and specific regulation by Fyn tyrosine kinase in mutant mice. Genes \& Dev. 9: 1909-1921.

Hardin, J.D., S. Boast, M. M endel sohn, K. de los Santos, and S.P. Goff. 1996. Transgenes encoding both type I and type IV c-abl proteins rescue the lethality of c-abl mutant mice. Oncogene 12: 2669-2677.

Henkemeyer, M., S.R., F.B. Gertler, and F.M. Hoffmann. 1990. A novel tyrosine kinase-independent function of Drosophila abl correlates with proper subcellular localization. Cell 63: 949-960.

Holmes, T.C., D.A. Fadool, R. Ren, and I.B. Levitan. 1996. Association of Src tyrosine kinase with a human potassium channel mediated by SH3 domain. Science 274: 2089-2091.

Ignelzi, M.A., D.R. Miller, P. Soriano, and P.F. Maness. 1994. Impaired neurite outgrowth of Src-minus neurons on the cell adhesion molecule L1. Neuron 12: 873-884.

Kamps, M. and B.M. Sefton. 1986. N either arginine nor histidine can carry out the function of Iysine-295 in the ATPbinding site of p60src. Mol. Cell Biol. 6: 751.

Kaplan, K.B., K.B. Bibbins, J.R. Swedlow, M. Arnaud, D.O. Morgan, and H.E. Varmus. 1994. Association of the amino-terminal half of c-Src with focal adhesions alters their properties and is regulated by phosphorylation of tyrosine 527. EMBO J. 13: 4745-4756.

Kaplan, K.B., J.R. Swedlow, D.O. Morgan, and H.E. Varmus. 1995. c-Src enhances the spreading of $\mathrm{src}^{-1-}$ fibroblasts on fibronectin by a kinase-independent mechanism. Genes \& Dev. 9: 1505-1517.

Kmiecik, T.E. and D. Shalloway. 1987. Activation and suppression of pp60c-src transforming ability by mutation of its pri- 
mary sites of tyrosine phosphorylation. Cell 49: 65-73.

Lakkakorpi, P. and H.K. Vaanenen. 1991. Kinetics of osteclast cytoskeleton during the resorption cycle in vitro. J. Bone Miner. Res. 6: 817-825.

Lee-Fruman, K.K., T.L. Collins, and S.J. Burakoff. 1996. Role of the Lck Src homology 2 and 3 domains in protein tyrosine phosphorylation. J. Biol. Chem. 271: 25003-25010.

Lev, S., H. Moreno, R. M artinez, P. Canoll, E. Peles, J. Musacchio, G. Plowman, B. Rudy, and J. Schlessinger. 1995. Protein tyrosine kinase PYK2 involved in $\mathrm{Ca}(2+)$-induced regulation of ion channel and MAP kinase functions. Nature 376: 737-745.

Levin, S.D., S.J. Anderson, K.A. Forbush, and R.M. Perlmutter. 1993. A dominant-negative transgene defines a role for p56 lck in thymopoiesis. EMBO J. 12: 1671-1680.

Lipsich, L.A., A.J. Lewis, and J.S. Brugge. 1983. Isolation of monoclonal antibodies tht recognize the transforming proteins of avian sarcoma viruses. J. Virol. 48: 352-360.

Lowe, C., T. Yoneda, B.F. Boyce, H. Chen, G.R. Mundy, and P. Soriano. 1993. Osteopetrosis in Src-deficient mice is due to an autonomous defect of osteoclasts. Proc. Natl. Acad. Sci. 90: 4485-4489.

Marchisio, P.C., L. N aldini, D. Cirillo, M.V. Primavera, A. Teti, and A. Zambonin-Zallone. 1984. Cell-substratum interactions of cultured avian osteoclasts is mediated by specific adhesion structures. J. Cell. Biol. 99: 1696-1705.

Mukhopadhyay, D., L. Tsiokas, X.M. Zhou, D. Foster, J.S. Brugge, and V.P. Sukhatme. 1995. Hypoxic induction of human vascular endothelial growth factor expression through c-Src activation. Nature 375: 577-581/

N eff, L., M. Amling, and R. Baron. 1996. cSrc deletion alters adhesion structures in the osteoclast: Redistribution of podosomes and formation of focal adhesions. J. Bone Miner. Res. 11: S290.

Pawson, T. and G.D. Gish. 1992. SH2 and SH 3 domains: From structure to function. Cell 71: 359-362.

Piwnica-Worms, H., K.B. Saundrs, T.M. Roberts, A.E. Smith, and S.H. Cheng. 1987. Tyrosine phosphorylation regulates the biochemical and biological properties of pp60c-src. Cell 49: 75-82.

Reddy, S.V., J.E. Hundley, J.J Windle, O. Alcantara, R. Linn, R.J. Leach, D.H. Boldt, and G.D. Roodman. 1995. Characterization of the mouse tartrate-resistant acid phosphatase (TRAP) gene promoter. J. Bone Miner. Res. 10: 601-606.

Schaller, M.D., J.D. Hildebrand, J.D. Shannon, J.W. Fox, R.R. Vines, and J.T. Parsons. 1994. Autophosphorylation of the focla adhesion kinase, pp125FAK, directs SH2-dependent binding of pp60src. Mol. Cell. Biol. 14: 1680-1688.

Schaller, M.D. and J. Parsons. 1994. Focal adhesion kinase and associated proteins. Curr. Opin. Cell Biol. 6: 705-710.

Schlaepfer, D.D., S.K. Hanks, T. Hunter, and P. van der Geer. 1994. Integrin-mediated signal transduction linked to Ras pathway by GRB2 binding to focal adhesion kinase. Nature 372: 786-791.

Schlaepfer, D.D., M .A. Broome, and T. Hunter. 1997. Fibronectin-stimulated signaling from a focal adhesion kinase-c-Src complex: Involvement of the GRB2, p130 ${ }^{\text {cas }}$ and N ck adaptor proteins. Mol. Cell. Biol. 17: 1702-1713.

Soriano, P., C. Montgomery, R. Geske, and A. Bradley. 1991. Targeted disruption of the c-src proto-oncogene leads to osteopetrosis in mice. Cell 64: 693-702.

Takahashi, N., H. Yamana, S. Yoshiki, G.D. Roodman, G.R. Mundy, S.J. Jones, A. Boyde, and T. Suda. 1988a. Osteoclastlike cell formation and its regulation by osteotropic hormones in mouse bone marrow cultures. Endocrinology 122: 1373-1382.
Takahashi, N., T. Akatsu, N. Udagawa, T. Sasaki, A. Yamaguchi, J. M osel ey, T.J. M artin, and T. Suda. 1988b. Osteoblastic cells are involved in osteoclast formation. Endocrinology 123: $2600-2602$.

Tanaka, S., M. Amling, L. N eff, A. Peyman, E. Uhlmann, J.B. Levy, and R. Baron. 1996. c-Cbl is downstream of c-Src in a signalling pathway necessary for bone resorption. Naure 383: 528-531.

Teti, A., P.C. M arschisio, and A. Zamonin Zallone. 1991. Clear zone in osteoclast function: Role of podosomes in regulation of bone-resorbing activity. Am. J. Physiol. 261: C1-7.

Twamley-Stein, G.M., R. Pepperkok, W. Ansorge, and S.A. Courtneidge. 1993. The Src family tyrosine kinases are required for platelet-derived growth factor-mediated signal transduction in NIH 3 T 3 cells. Proc. Natl. Acad. Sci. 90: 7696-7700.

Vuori, K., H. Hirai, S. Aizawa, and E. Ruoslahti. 1996. Introduction of p130cas signaling complex formation upon integrinmediated cell adhesion: A role for Src family kinases. Mol. Cell. Biol. 16: 2606-2613.

Xu, H. and D.R. Littman. 1993. A. kinase-independent function of Lck in potentiating antigen-specific $T$ cell activation. Cell 74: 633-643.

Yu, X.-M., R. Askalan, G.J. Keil, and M.W. Salter. 1997. N MDA channel regulation by channel-associated protein tyrosine kinase Src. Scienc 275: 674-678. 


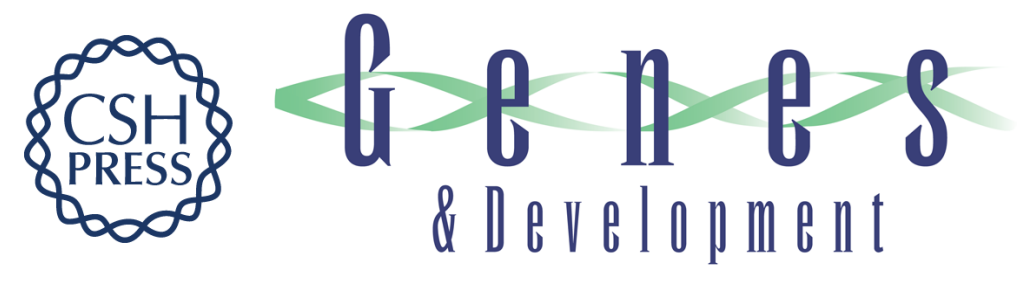

\section{Rescue of osteoclast function by transgenic expression of kinase-deficient Src in src-/- mutant mice}

Pamela L. Schwartzberg, Lianping Xing, Oskar Hoffmann, et al.

Genes Dev. 1997, 11:

Access the most recent version at doi:10.1101/gad.11.21.2835

References This article cites 42 articles, 16 of which can be accessed free at: http://genesdev.cshlp.org/content/11/21/2835.full.html\#ref-list-1

License

Email Alerting

Receive free email alerts when new articles cite this article - sign up in the box at the top Service right corner of the article or click here.

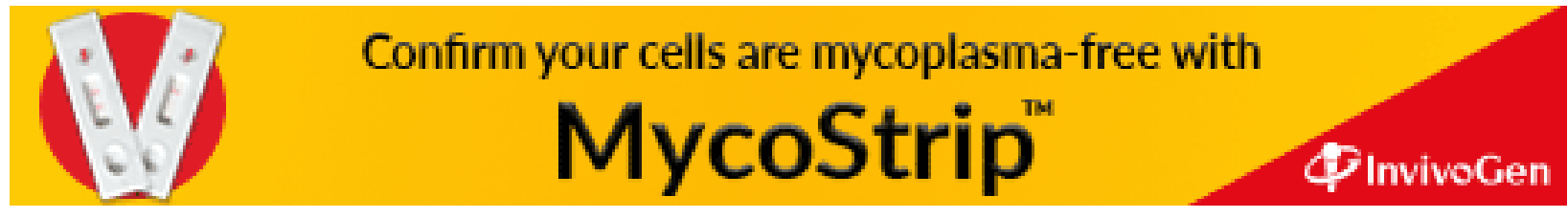

